\title{
ENGINE COMBUSTION EFFICIENCY AND PERFORMANCE OF EXHAUST PIPE FUEL PREHEATING SYSTEM
}

\author{
Azamataufiq Budiprasojo ${ }^{1}$, Andik Irawan ${ }^{2}$ \\ 1,2 Jurusan Teknik Politeknik Negeri Jember \\ JIn. Mastrip PoBOX 164 Jember 68141 Indonesia \\ E-mail: azamataufig@polije.ac.id
}

\begin{abstract}
The Exhaust Pipe Preheated Fuel System (EP2FS) is a fuel preheating system that utilizes wasted heat from the muffler. Fuel heating aims to improve the homogeneity of fuel and air mixtures to improve the combustion process in the engine. Making EP2FS requires careful design and calculation because the fuel temperature should not exceed $60^{\circ} \mathrm{C}$ so as not to evaporate. Design and calculation, using heat transfer theory of helical heat exchanger. $A$ ready-made system will be applied in motor vehicles to be tested for combustion efficiency and performance.
\end{abstract}

Keywords: Fuel Preheating, Engine Performance, Helical Heat Exchanger.

PENDAHULUAN

Dalam bidang rekayasa engine, engine dengan performa tinggi namun irit, bisa diciptakan dengan menyempurnakan proses pembakaran bahan bakar di ruang bakar. Pembakaran di ruang bakar dikatakan sempurna apabila seluruh bahan bakar yang masuk ke ruang bakar terbakar seluruhnya. [1].

Penelitian terkait usaha perbaikan kualitas pembakaran telah dilakukan oleh beberapa peneliti, salah satunya menyimpulkan bahwa penghematan bahan bakar dapat dilakukan, dengan beberapa metode yang meliputi metode magnet, metode pemanasaan awal (preheating), metode gabungan (variasi pemanasan dan elektromagnetik), metode cyclone, metode menaikan kadar oktan bahan bakar, metode penambahan pasokan udara, dan metode kondisi mesin.[2]

Metode pemanasan awal sebagai usaha perbaikan kualitas pembakaran pernah dilakukan dengan Upaya pemberian panas awal pada bahan bakar (fuel preheating). Penelitian berfokus pada pengaruh pemanasan bahan bakar bensin melalui media pipa tembaga di dalam upper tank radiator terhadap emisi gas buang CO pada mesin Daihatsu Taruna tahun 2000. Hasil analisa statistik menunjukkan pengaruh yang signifikan pada taraf signifikansi $1 \%$ yaitu pada pemanasan bahan bakar bensin dengan media pipa tembaga di dalam upper tank radiator [2].

Pembakaran dengan menggunakan bahan bakar yang telah terlebih dahulu dipanaskan dapat lebih baik karena bahan bakar dalam fase cair jenuh lebih mudah terbakar bila dibandingkan dalam fase cairnya. Pemanasan bahan bakar bertujuan meningkatkan homogenitas campuran bahan bakar dan udara untuk menyempurnakan proses pembakaran di mesin [3].

Penggunaan radiator sebagai sumber pemanas awal bagi sistem pemanas bahan bakar merupakan ide yang amat baik, karena memanfaatkan rugi panas dari mesin yang tidak terpakai menjadi suatu sumber energi yang terpakai. Suatu siklus pemakaian ulang energi (recycling of energy) terjadi pada sistem ini. Energi yang terbuang dapat diubah menjadi energi yang bermanfaat [4].

Sayangnya tidak semua kendaraan menggunakan radiator, sehingga perlu dipikirkan suatu alternatif sistem pemanasan awal bahan bakar yang dapat diaplikasikan pada kendaraan yang lebih umum. Berangkat dari ini maka dibuatlah penelitian yang berisi perancangan exhaust pipe preheating fuel system (EP2FS) berbasis alat penukar kalor tipe pipa dingin sebagai upaya peningkatan efisiensi pembakaran engine.

Penelitian kali ini ingin mendesain suatu sistem pemanas awal bahan bakar menggunakan panas terbuang mesin yang dibuang melalui knalpot sebagai sumber 
panasnya. Penelitian ini diharapkan mampu membuat suatu sistem pemanas awal bahan bakar yang dapat diaplikasikan pada kendaraan secara lebih umum (tidak hanya pada kendaraan dengan radiator).

Perhitungan untuk mendesain EP2FS menggunakan persamaan persamaan dalam ilmu heat transfer khususnya tentang heat exchanger [5]. Sumber panas yang digunakan dalam kasus ini adalah panas dari flue gas yang mengalir dalam suatu pipa dengan temperature tinggi. Panas dari flue gas akan dimanfaatkan untuk memanaskan bahan bakar sebagai fluida kerja. Temperatur dari fluida kerja adalah rendah dan fluida kerja ini mengalir dalam pipa yang memiliki temperature rendah pula [6].

Pembuatan EP2FS memerlukan desain dan perhitungan yang cermat karena temperatur bahan bakar tidak boleh melebihi $60^{\circ} \mathrm{C}$ agar tidak menguap. Desain dan perhitungan menggunakan teori perpindahan panas alat penukar kalor tipe helical (Helical Heat Exchanger) [7].

Setelah didapatkan suatu EP2FS yang adalah sistem pemanas awal bahan bakar dengan panas knalpot, maka akan diteliti juga seberapa besar pengaruh dari pengaplikasian sistem ini pada engine dilihat dari kadar emisi, performa engine, serta effisiensi pembakarannya.

\section{METODOLOGI PENELITIAN}

Penelitian ini menggunakan pendekatan eksperiment (Research Method). Pengumpulan data dilakukan dengan mengadakan penelitian secara langsung pada obyek penelitian. Gambar 1 adalah instalasi penelitian.

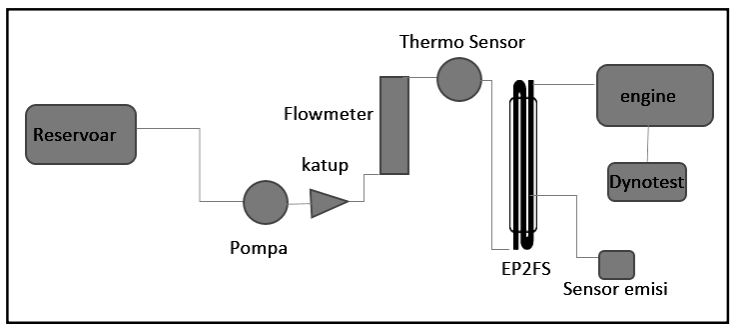

Gambar 1 Instalasi Penelitian
Adapun tahapan penelitian ditunjukkan oleh diagram alir berikut :

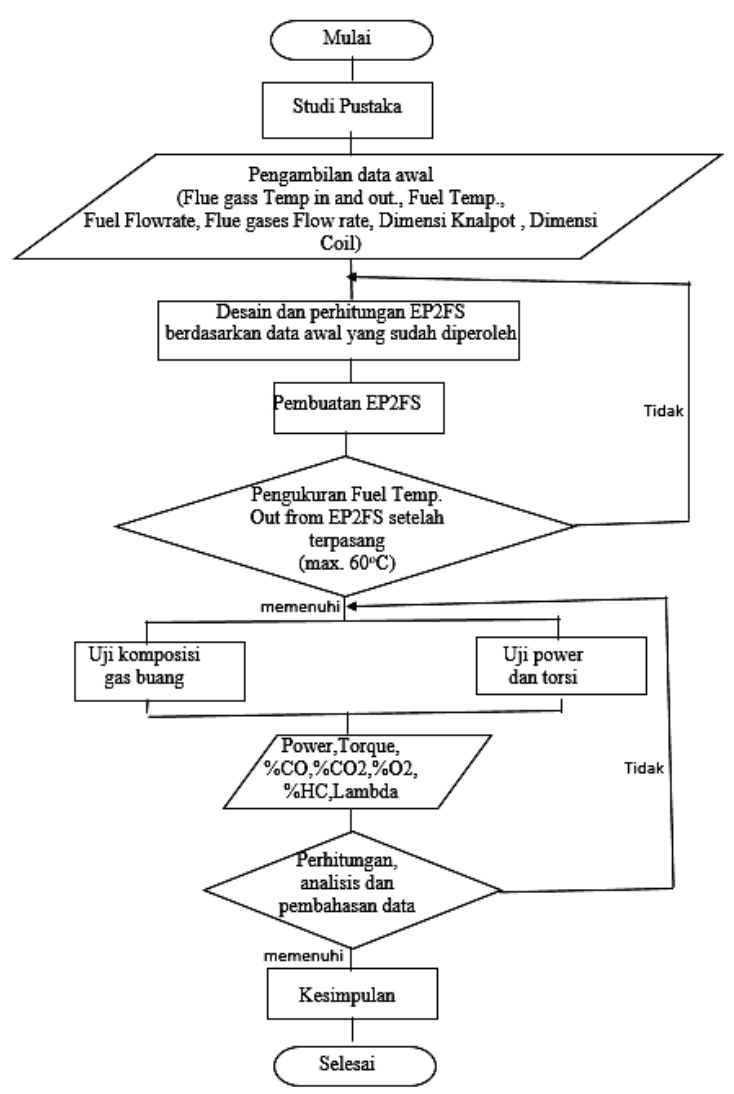

Gambar 2 Diagram alir penelitian

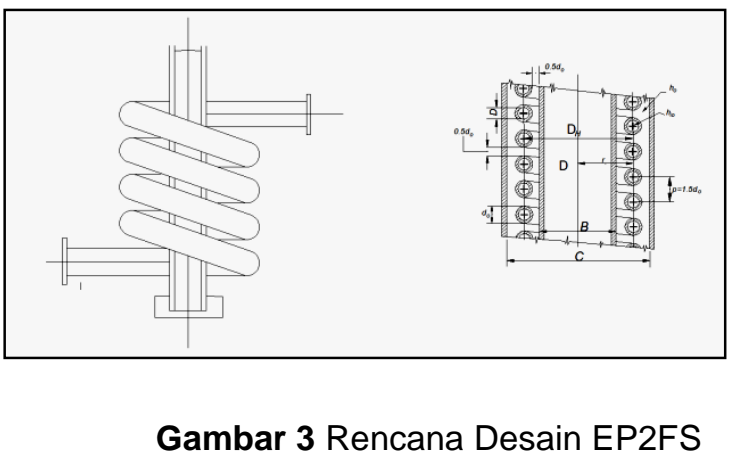

Perhitungan:

Perhitungan EP2FS menggunakan perhitungan heat exchanger tipe helical [8] yang disesuaikan dengan kondisi pada instalasi. 


\section{Nomenclature}

A Area untuk transfer panas, $\mathrm{m}^{2}$

$D c_{\text {in }} \quad$ Diameter dalam dari coil, $\mathrm{m}$

$D c_{\text {out }} \quad$ Diameter luar dari coil, $\mathrm{m}$

$D e_{\text {in }} \quad$ Diameter dalam dari knalpot, $\mathrm{m}$

$D e_{\text {out }} \quad$ Diameter luar dari knalpot, $m$

$h_{f} \quad$ Koefisien perpindahan panas konveksi dari Bahan bakar

$h_{f g} \quad$ Koefisien perpindahan panas konveksi dari Flue gas

$K_{c} \quad$ Koefisien perpindahan panas konduksi dari coil

$K_{e} \quad$ Koefisien perpindahan panas konduksi dari exhaust pipa

$k_{\text {coil }} \quad$ Konduktivitas panas dari coil, $\mathrm{kcal} /(\mathrm{h})\left(\mathrm{m}^{2}\right)\left({ }^{\circ} \mathrm{C}\right)$

$k$ expipe Konduktivitas panas dari exhaust pipe, $\mathrm{kcal} /(\mathrm{h})\left(\mathrm{m}^{2}\right)\left({ }^{\circ} \mathrm{C}\right)$

$L \quad$ Panjang coil helical yang diperlukan untuk membentuk putaran $N$, m

$M \quad$ Laju aliran cairan, $\mathrm{kg} / \mathrm{h}$

$N \quad$ Angka teoritis dari putaran helical coil

$n \quad$ Angka riil dari putaran coil yang dibutuhkan untuk tugas proses panas yang diberikan ( $N$ dibulatkan ke integer tertinggi selanjutnya)

$N_{R e} \quad$ Angka Reynolds, Dup/ $\mu$ atau $D G / \mu$, dimensionless

Q Beban panas, $\mathrm{kcal} / \mathrm{h}$

$R_{a} \quad$ Faktor fouling shell-side, (h) $\left(\mathrm{m}^{2}\right)\left({ }^{\circ} \mathrm{C}\right) / \mathrm{kcal}$

$R_{t} \quad$ Faktor fouling tube-side, (h) $\left(\mathrm{m}^{2}\right)\left({ }^{\circ} \mathrm{C}\right) / \mathrm{kcal}$

$R_{f} \quad$ Angka Reynolds bahan bakar, dimensionless

$R e_{f g} \quad$ Angka Reynolds flue gas, dimensionless

$\mu \quad$ Viskositas cairan pada rata-rata suhu bulk-fluid, $\mathrm{kg} /(\mathrm{m})(\mathrm{h})$

1/U Hambatan thermal total, (h) $\left(\mathrm{m}^{2}\right)\left({ }^{\circ} \mathrm{C}\right) / \mathrm{kcal}$

$u \quad$ Kecepatan cairan, $\mathrm{m} / \mathrm{h}$

$U \quad$ Koefisien perpindahan panas total, $\mathrm{kcal} /(\mathrm{h})\left(\mathrm{m}^{2}\right)\left({ }^{\circ} \mathrm{C}\right)$

$\rho \quad$ Densitas cairan, $\mathrm{kg} / \mathrm{m}^{3}$

$\rho_{f} \quad$ Densitas bahan bakar, $\mathrm{kg} / \mathrm{m}^{3}$

$\rho_{f g} \quad$ Densitas flue gas, $\mathrm{kg} / \mathrm{m}^{3}$

$\Delta \mathrm{X}_{\mathrm{c}} \quad$ Tebal pipa tembaga, $\mathrm{m}$

$\Delta \mathrm{X}_{\mathrm{e}} \quad$ Tebal pipa knalpot, $\mathrm{m}$
1. Koefisien perpindahan panas konveksi dari Flue gas $\left(\mathrm{h}_{\mathrm{fg}}\right)$

Diasumsikan aliran dalam pipa adalah fully development flow.

$$
R e_{f g}=\frac{D_{\text {in ep }} \cdot \mathrm{u}_{\text {gas }} \cdot 3600 \cdot \rho_{\text {gas }}}{\mu_{\text {gas }}}
$$

Perhitungan perpindahan panas

konveksinya mengunakan persamaan :

$$
\mathrm{h}_{\mathrm{fg}}=0,6 . R e_{f g}{ }^{0,5} \cdot \operatorname{Pr}_{\mathrm{fg}}{ }^{0,31}
$$

2. Koefisien perpindahan panas konveksi dari Bahan bakar $\left(\mathrm{h}_{\mathrm{f}}\right)$

Diasumsikan aliran dalam pipa adalah fully development flow.

$R e_{f}=\frac{D_{\text {in coil }} \cdot \mathrm{u}_{\text {fuel }} \cdot 3600 \cdot \rho_{\text {fuel }}}{\mu_{\text {fuel }}}$

Perhitungan perpindahan panas

konveksinya mengunakan persamaan :

$$
\mathrm{h}_{\mathrm{f}}=0,6 . R e_{f} 0,5 . P r_{f} 0,31
$$

3. Koefisien perpindahan panas konduksi pipa tembaga setebal $\Delta X c(\mathrm{Kc})$

Tebal pipa tembaga $\Delta X c$ :

$\Delta X c=$ Dc out $-\mathrm{Dc}$ in

Koefisien perpindahan panas :

$$
k c=\frac{K_{\text {coil }}}{\Delta X c}
$$

4. Koefisien perpindahan panas konduksi pipa knalpot setebal $\Delta X e(\mathrm{Ke})$

Tebal pipa knalpot Dxce :

$\Delta X e=\mathrm{De}$ out $-\mathrm{De}$ in

Koefisien perpindahan panas :

$k e=\frac{K_{\text {ex.pipe }}}{\Delta X e}=\frac{396}{0.0031}$

5. Hambatan thermal total $(1 / \mathrm{U})$

$\frac{1}{U}=\frac{1}{h_{f g}}+\frac{1}{h_{f g}}+\frac{\Delta X c}{K_{\text {coil }}}+\frac{\Delta X e}{K_{\text {ex.pipe }}}+R a+R t(9)$ Faktor fouling, $R_{t}$ dan $R_{a}$, merupakan suatu konstanta tergantung dari sifat alami fluida, campuran dalam fluida, temperatur operasi fluida serta kecepatan dari fluida.

6. Koefisien perpindahan panas total (U)

$U=1 /(1 / U)$

7. Log Mean Temperature Difference (LMTD)

$\left.=\frac{\left(T_{\text {in Flue gas }}-T_{\text {in }} \text { Fuel }\right)-\left(T_{\text {out }} \text { Flue gas }-T_{\text {out }} \text { Fuel }\right)}{\text { Ln }\left(\left(T_{\text {in }} \text { Flue gas }-T_{\text {in }} \text { Fuel }\right) /\left(T_{\text {out }} \text { Flue gas }-T_{\text {out }} \text { Fuel }\right)\right.}\right)$ 
8. Kalor yang di alirkan $(Q)$

$\mathrm{Q}=(\mathrm{U}) \times \mathrm{A} \times(\mathrm{T}$ out Fuel $-\mathrm{T}$ in Fuel $)$

9. Area yang dibutuhkan untuk menghasilkan $\mathrm{Q}(\mathrm{A})$

$$
A=\frac{\mathrm{Q}}{U \times L M T D}
$$

Area ini adalah area dengan asumsi selurug bagian coil tembaga bersentugan dengan pipa suber panas. Pada kasus ini area yang bersentuhan hanya $1 / 3$ saja. Sehingga area nyata yang bersentuhan untuk mengamoadir $1 / 3$ contact $=3 \times \mathrm{A}$

10. Panjang teoritis Coil yang dibutuhkan

$$
L=N \sqrt{(2 \pi r)^{2}+p^{2}}
$$

11. Angka teoritis dari putaran helical coil $(\mathrm{N})$

$$
N=\frac{\mathrm{A}}{\mathrm{Q} \times \mathrm{LMTD}}
$$

\section{HASIL DAN PEMBAHASAN}

Desain EP2FS memerlukan beberapa properties. Nilai dari properties diambil dari pengukuran langsung dan dari literatur. Properties yang akan digunakan untu perhitungan disajikan dalam tabel 1 .

Tabel 1 Physical Properties

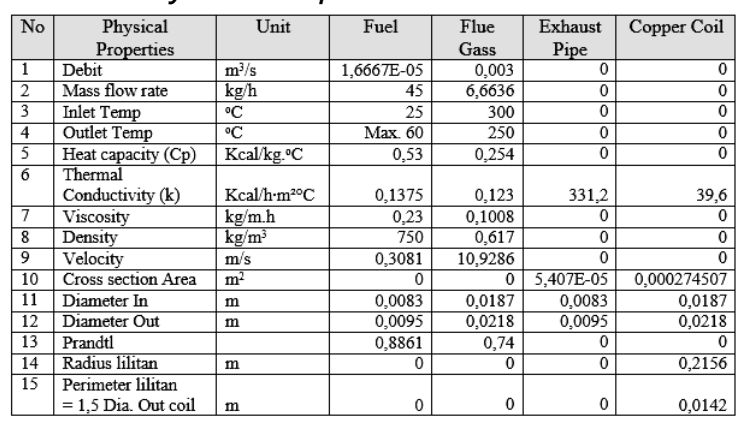

Dari tabel 1 dilakukan perhitungan menggunakan persamaan persamaan yang pada metode penelitian. Untuk memudahkan proses perhitungan digunakan aplikasi pengolah data. Hasil dari perhitungan didapatkan bahwa untuk membuat EP2FS sebagai pemanas bahan bakar bensin agar mencapai temperatur $60^{\circ} \mathrm{C}$ diperlukan pipa tembaga dengan diameter luar $9.5 \mathrm{~mm}$ serta diameter dalam $8.3 \mathrm{~mm}$ dan panjang $40 \mathrm{~cm}$. Pipa tembaga dengan dimensi ini diproduksi oleh industri dengan ukuran $5 / 8$ inch.
Bensin mulai berubah menjadi uap pada temperature $60^{\circ} \mathrm{C}$ [9]. Pada penelitian ini suhu $60^{\circ} \mathrm{C}$ dijadikan suhu maksimal dari bahan bakar saat keluar EP2FS. Untuk menjamin suhu yang keluar EP2FS adalah maksimal 60 ${ }^{\circ} \mathrm{C}$ maka perlu diuji temperature bahan bakar keluar EP2FS. Pengujian ini dilakukan setelah EP2FS dipasang di sepeda motor kemudian dinyalakan dengan variasi RPM. Berikut adalah hasil pengujiannya.

\begin{tabular}{|c|c|c|c|c|c|c|c|c|c|}
\hline \multirow{13}{*}{$\begin{array}{c}\text { Temperatur } \\
\left({ }^{\circ} \mathrm{C}\right)\end{array}$} & \multicolumn{9}{|c|}{ RPM } \\
\hline & \multicolumn{3}{|c|}{1200} & \multicolumn{3}{|c|}{4500} & \multicolumn{3}{|c|}{7500} \\
\hline & 1 & 2 & 3 & 1 & 2 & 3 & 1 & 2 & 3 \\
\hline & 25 & 25.2 & 25.4 & 40 & 40.2 & 40.4 & 55 & 55.2 & 55.4 \\
\hline & 25.3 & 25.5 & 25.7 & 40.3 & 40.5 & 40.7 & 55.3 & 55.5 & 55.7 \\
\hline & 26.1 & 26.3 & 26.5 & 41.1 & 41.3 & 41.5 & 56.1 & 56.3 & 56.5 \\
\hline & 26.6 & 26.8 & 27 & 41.6 & 41.8 & 42 & 56.6 & 56.8 & 57 \\
\hline & 27.5 & 27.7 & 27.9 & 42.5 & 42.7 & 42.9 & 57.5 & 57.7 & 57.9 \\
\hline & 29.5 & 29.7 & 29.9 & 44.5 & 44.7 & 44.9 & 59.5 & 59.7 & 59.9 \\
\hline & 30.7 & 30.9 & 31.1 & 45.7 & 45.9 & 46.1 & 60.7 & 60.9 & 61.1 \\
\hline & 32.1 & 32.3 & 32.5 & 47.1 & 47.3 & 47.5 & 62.1 & 62.3 & 62.5 \\
\hline & 33.7 & 33.9 & 34.1 & 48.7 & 48.9 & 49.1 & 63.7 & 63.9 & 64.1 \\
\hline & \multicolumn{3}{|c|}{ Average $=28.7$} & \multicolumn{3}{|c|}{ Average $=43.7$} & \multicolumn{3}{|c|}{ Average $=59.7$} \\
\hline
\end{tabular}

Tabel 2 Temperatur bahan bakar keluar EP2FS

Dari tabel terlihat bahwa, dengan menggunakan EP2FS temperatur maksimal bahan bakar keluar EP2FS adalah $59.7^{\circ} \mathrm{C}$ dibawah $60^{\circ} \mathrm{C}$.

Setelah diyakinkah bahwa EP2FS mampu memanaskan bensin dengan suhu maksimal dibawah $60^{\circ} \mathrm{C}$, maka kemudian EP2FS dipasang pada kendaraan untuk diuji performa serta gas buang untuk menentukan berapa efisiensi pembakarannya.

Hasil dari pengujian ini disajikan dalam grafik grafik berikut.

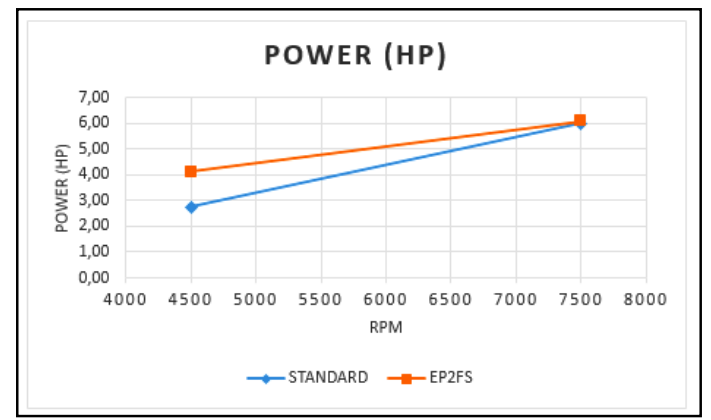

Gambar 3 Grafik Power vs rpm 


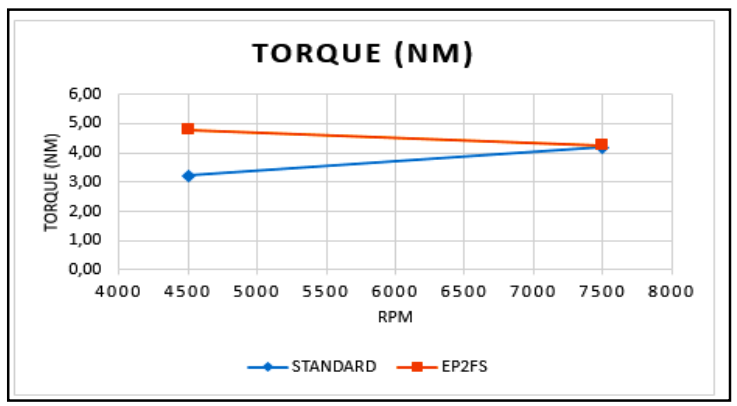

Gambar 4 Grafik Torque vs rpm

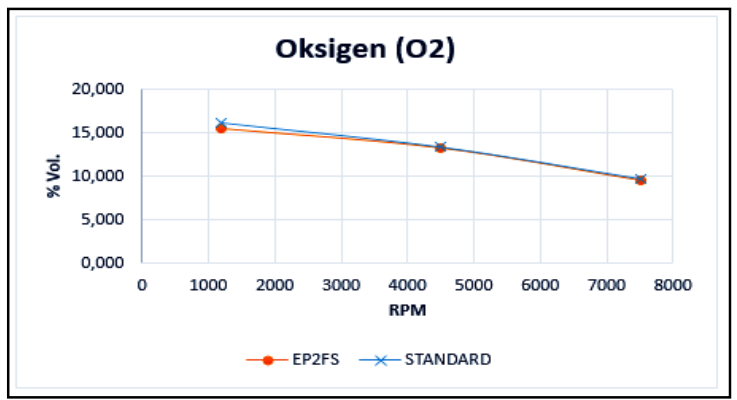

Gambar 5 Grafik volume gas buang Oksigen vs rpm

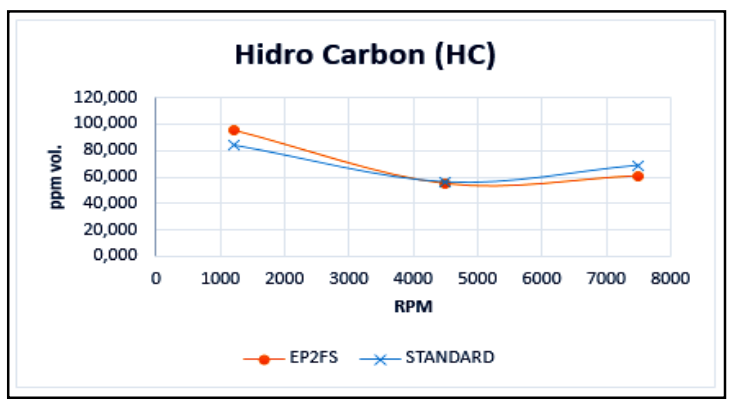

Gambar 6 Grafik volume gas buang Hidrocarbon vs rpm

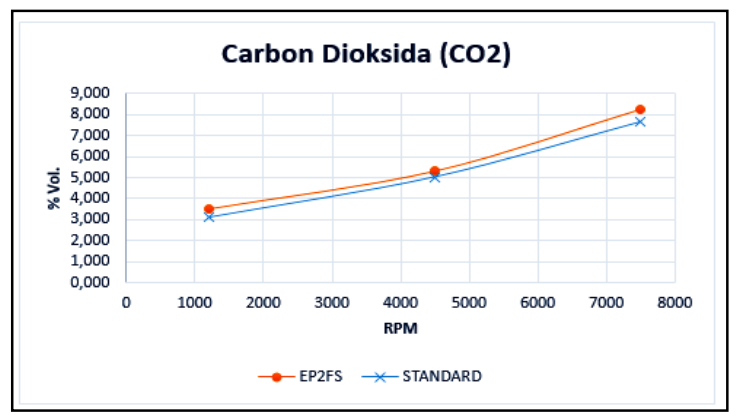

Gambar 7 Grafik volume gas buang karbondioksida vs rpm

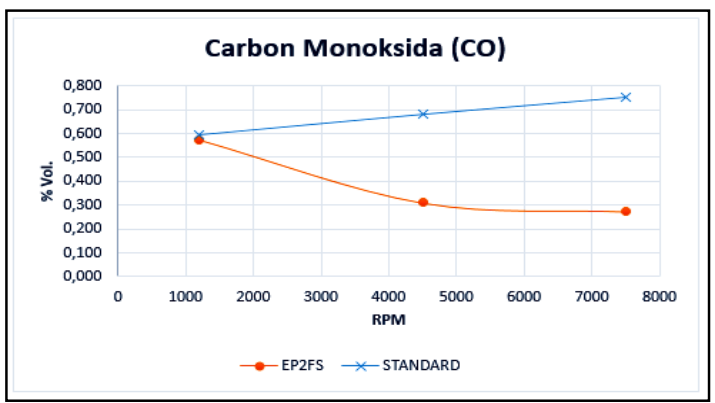

Gambar 8 Grafik volume gas buang karbon monoksida vs rpm

Effisiensi pembakaran adalah perbandingan antara volume gas $\mathrm{CO}_{2}$ dibandingkan dengan jumlah volume $\mathrm{CO}_{2}$ dan $\mathrm{CO}$ yang dinyatakan dalam prosen.

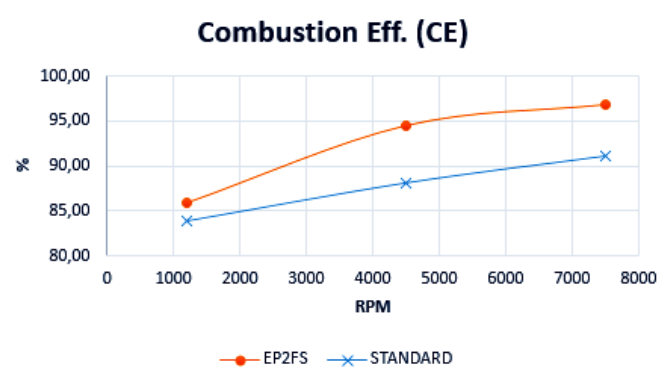

Gambar 9 Grafik combustion efficiency vs rpm

\section{Analisis Keuntungan}

Mesin yang efisien adalah mesin yang mempunyai sistem penyalur bahan bakar yang mampu membuat campuran udara dan bahan bakar tercampur secara homogen diruang bakar. Homogen disini artinya adalah seragam yang diindikasikan dengan besar partikel bahan bakar (droplet) berukuran sangat kecil sehingga lebih mudah bercampur dengan partikel oksigen untuk dibakar. Teknologi injeksi merupakan teknologi yang dikembangkan untuk tujuan ini.

Droplet juga bisa berbentuk lebih kecil pada fluida dengan temperatur yang lebih tinggi, viskositas rendah dan tegangan permukaan rendah. Berlandas dari tujuan ini maka pemanasan bahan bakar dilakukan. Meningkatnya suhu pemanasan bahan bakar dapat membuat lapisan bahan bakar semakin mudah terlepas karena adanya proses memperkecil viskositas dan tegangan permukaan. Perubahan parameter ini dapat membuat partikel bahan bakar akan lebih aktif 
untuk bercampur dengan udara. Imbas dari hal ini adalah pembakaran yang terjadi semakin sempurna karena ada perbaikan dari pencampuran bahan bakar dan udara.

Pemanasan bahan bakar harus dilakukan dengan cermat karena sifat dari bahan bakar yang mudah menguap. Bahan bakar menguap pada temperatur $70^{\circ} \mathrm{C}$. Oleh karenanya pemanas hanya boleh memanasi bahan bakar sampai mencapai temperatur maksimal $70^{\circ} \mathrm{C}$.

Pada pra penelitian pernah dicoba memanaskan bahan bakar hingga mencapai suhu $90^{\circ} \mathrm{C}$ dengan memanfaatkan pemanas yang berasal dari listrik DC. Pemanas kemudian dipasang di kendaraan roda dua dan diuji. Hasilnya adalah bahan bakar berubah menjadi uap dan mesin susah untuk idle yang kemudian disusul dengan mesin mati. Selain itu sumber tegangan DC (Aki) lebih cepat berkurang tegangannya karena harus menyuplai peralatan tambahan pemanas.

Pembuatan alat pemanas bahan bakar yang menggunakan sumber panas dari knalpot harus didesain dan dihitung secara cermat karena output temperatur bahan bakar dari alat pemanas tidak boleh melebihi $60^{\circ} \mathrm{C}$ (dibawah dari temperatur penguapan bahan bakar sebesar $70^{\circ} \mathrm{C}$ ). Pada pengambilan data temperatur knalpot sebagai sumber panas, didapatkan bahwa temperatur maksimal knalpot dari kendaraan uji adalah $450{ }^{\circ} \mathrm{C}$ sangat jauh lebih tinggi dari temperatur bahan bakar yang ditargetkan.

Dari perhitungan didapatkan bahwa untuk membuat EP2FS sebagai pemanas bahan bakar bensin agar mencapai temperatur $60{ }^{\circ} \mathrm{C}$ diperlukan pipa tembaga dengan diameter luar $9.5 \mathrm{~mm}$ serta diameter dalam $8.3 \mathrm{~mm}$ dan panjang $40 \mathrm{~cm}$. EP2FS Berdesain lilitan berbentuk coil dengan penambahan insulator pada bagian sisi luar coil. Jumlah lilitan adalah 2,5 lilitan. Pipa tembaga dengan dimensi ini diproduksi oleh industri dengan ukuran $5 / 8$ inch.

Untuk menjamin suhu yang keluar EP2FS adalah maksimal $60{ }^{\circ} \mathrm{C}$ maka perlu diuji temperature bahan bakar keluar EP2FS. Pengujian ini dilakukan setelah EP2FS dipasang di sepeda motor kemudian dinyalakan dengan variasi RPM. Dari tabel terlihat bahwa, dengan menggunakan EP2FS temperatur maksimal bahan bakar keluar EP2FS adalah $59.7{ }^{\circ} \mathrm{C}$ dan berada dibawah dari temperatur maksimal bahan bakar yang diijinkan yaitu $60^{\circ} \mathrm{C}$. Jadi dapat disimpulkan bahwa perhitungan dan desain EP2FS sudah sesuai target.

Dari pengujian Torsi dan daya didapatkan fakta bahwa pada kendaraan uji yang menggunakan EP2FS terdapat peningkatan torsi dan daya yang cukup signifikan pada putaran mesin rendah. Ini memiliki arti bahwa akselerasi dan kecepatan dari kendaraan meningkat. Pada putaran mesin yang tinggi didapatkan data bahwa torsi daya cenderung tidak memiliki perbedaan yang signifikan antara kendaraan yang menggunakan EP2FS dan kendaraan standar. Kemungkinan penyebab dari tidak signifikannya perbedaan torsi dan daya dari kendaraan EP2FS dan standar adalah karena pada putaran mesin bahan bakar dari kendaraan standar sudah mendapatkan panas yang cukup untuk berubah menjadi droplet yang homogen dari panas mesin yang cukup tinggi akibat gesekan diruang bakar pada kecepatan pergerakan piston yang cepat. Peningkatan power dan torsi pada mesin dengan menggunakan EP2FS adalah $40 \%$ pada putaran mesin rendah dan $1.5 \%$ pada putaran mesin tinggi.

Emisi $\mathrm{H}-\mathrm{C}$ atau hidrokarbon erat kaitannya dengan berapa banyak bahan bakar yang tidak terbakar karena kurang baiknya pencampuran antara droplet bahan bakar dan molekul oksigen. Emisi $\mathrm{CO}$ atau karbon monoksida paling banyak menonjol perbedaannya dan paling berbahaya di antara emisi dari mesin lainnya. Jumlah $\mathrm{CO}$ yang tinggi dapat terjadi karena bahan bakar kekurangan oksigen dalam pembakaran hidrokarbon.

Untuk Nox tidak tercatat karena peran dari catalyc converter pada sisi silincer muffler knalpot. Efisisiensi pembakaran yang didapatkan dari pemakaian EP2FS adalah meningkat $6 \%$ dari standar.

\section{Analisis Kerugian}

Dengan pemakaian sistem EP2FS ada beberapa kekhawatiran yang mungkin perlu diteliti lebih lanjut yaitu bahwa dengan pemanasan bahan bakar akan terjadi perubahan viskositas dari bahan bakar. 
Viskositas fluida bahan bakar berbanding terbalik dengan temperatur. Meskipun meningkatkan temperatur bahan bakar dapat menurunkan viskositasnya sehingga dapat memperkecil ukuran droplet dan meningkatkan homogenitas dari bahan bakar, namun itu akan mempengaruhi proses pelumasan.

Temperatur ruang bakar juga disinyalir akan semakin meningkat dengan semakin baiknya proses pembakaran sehingga perlu dipikirkan modifikasi pada sistem pendinginan untuk dapat mengatasi kenaikan temperatur ruang bakar. Durabilitas mesin erat kaitannya dengan suhu kerja mesin dan pendinginannya.

Pengaplikasian pada kendaraan yang menggunakan injeksi perlu diteliti lebih lanjut. Karena sistem injeksi bekerja dengan memakai peranti elektronik. Pemakaian EP2FS dikhawatirkan memiliki dampak pada peranti elektronik pada sistem injeksi.

\section{KESIMPULAN}

Ada beberapa hal yang dapat disimpulkan dari penelitian ini:

1. Dari perhitungan didapatkan bahwa untuk membuat EP2FS sebagai pemanas bahan bakar bensin agar mencapai temperatur $60 \quad{ }^{\circ} \mathrm{C}$ diperlukan pipa tembaga dengan diameter luar $9.5 \mathrm{~mm}$ serta diameter dalam $8.3 \mathrm{~mm}$ dan panjang $40 \mathrm{~cm}$. EP2FS Berdesain lilitan berbentuk coil dengan penambahan insulator pada bagian sisi luar coil. Jumlah lilitan adalah 2,5 lilitan. Pipa tembaga dengan dimensi ini diproduksi oleh industri dengan ukuran 5/8 inch.

2. Temperatur EP2FS maksimal bahan bakar keluar EP2FS adalah $59.7{ }^{\circ} \mathrm{C}$ dan berada dibawah dari temperatur maksimal bahan bakar yang diijinkan yaitu $60^{\circ} \mathrm{C}$.

3. Dari pengujian Torsi dan daya didapatkan fakta bahwa pada kendaraan uji yang menggunakan EP2FS terdapat peningkatan torsi dan daya yang cukup signifikan pada putaran mesin rendah. Ini memiliki arti bahwa akselerasi dan kecepatan dari kendaraan meningkat.

4. Peningkatan power dan torsi pada mesin dengan menggunakan EP2FS adalah $40 \%$ pada putaran mesin rendah dan $1.5 \%$ pada putaran mesin tinggi.
5. Efisisiensi pembakaran yang didapatkan dari pemakaian EP2FS adalah meningkat $6 \%$ dari standar.

\section{DAFTAR PUSTAKA}

[1] Willard W. Pulkrabek. Engineering Fundamentals of the Internal Combustion Engine. New Jersey.Hal. 229.

[2] Sudirman, Urip. 2006. Metode Tepat Menghemat Bahan Bakar (Bensin) Mobil. Jakarta : Kawan pustaka

[3] Brenda Brevitt. 2002. Alternative Vehicle Fuels, Science Environment Section, House of Commons Library, Research Paper 02/11.

[4] Kern, D. Q., Process Heat Transfer, McGraw-Hill, New York 2000

[5] Coates, J. and Pressburg, B. S., Heat transfer to moving fluids, Chemical Engineering Journal 2009, page 67-72

[6] Edward, M. F., others, Heat transfer and pressure drop characteristic pf a plate exchanger using newtonian and non newtonian liquids, Chemical Engineering Journal 2004, page 286-293

[7] Dimoplon, W. Finding the length of helical coils, Chemical Engineering Journal 2008

[8] Patil, Ramachandra K., others, Designing a helical-coil heat exchanger, Chemical Engineering Journal, page 85-88 Desember 2009

[9] R.R. Saraf, S.S.Thipse and P.K.Saxena. 2009. Comparative Emission Analysis of Gasoline/LPG Automotive Bifuel Engine. International Journal of Civil and Environmental Engineering 1:4 2009. 